\title{
Using Improprieties to Pursue Intimacy in Speed-dating Interactions
}

\author{
Neill Korobov ${ }^{1} \&$ Justin Laplante $^{1}$ \\ ${ }^{1}$ Psychology Department, University of West Georgia, Carrollton, GA, USA \\ Correspondence: Neill Korobov, Psychology Department, University of West Georgia, Carrollton, GA, 30118. \\ Tel: 1-678-839-0608. E-mail: Nkorobov@westga.edu
}

Received: January 4, 2013 Accepted: January 17, 2013 Available online: January 24, 2013

doi:10.11114/smc.v1i1.49 URL: http://dx.doi.org/10.11114/smc.v1i1.49

\begin{abstract}
This study focuses on how potential romantic partners in speed-dating interactions use improprieties to create relational affiliation and thus pursue intimacy. Within speed-dating interactions, improprieties are viewed as potentially relationally constructive, as they allow speakers to display shared cultural understandings about categories of romantic partner or partnerships. Drawing on a corpus of 72 speed-dates involving 24 participants (12 male; 12 female), a sequential discursive approach was used to analyze how two particular types of impropriety, negative category attributions of non-present others and insults to the present conversational partner, were consequential social actions for creating affective mutual affiliation. The general, albeit surprising, finding is that far from being adversarial, improprieties tended to be useful for pursuing intimacy precisely because they presented interactive trouble. Successfully navigating the interactive trouble seemed to increase a subjectively shared sense of familiarity. The study reveals that non-normative (i.e., less polite) forms of social action may serve as preliminaries for intimacy in first encounters between potential romantic partners.
\end{abstract}

Keywords: improprieties, intimacy, affiliation, discursive, speed-dating, romantic relationship

\section{Introduction}

Within communicative approaches to interpersonal relations, scholars are increasingly shifting from away from viewing relationships as things we have, and towards a view of relationships as things that we do, moment by moment, in and through interaction (Conroy, 1999; Goldsmith \& Baxter, 1996; Mandelbaum, 1987, 2003). Relationships are seen as "collections of communicative practices" (Mandelbaum, 2003, p. 217), where discourse is the constitutive fabric, not the output of pre-established social structural entities, roles or categories. Discerning how relationships are done from looking at the ways talk is produced is, however, no easy task. It requires showing that people are not simply talking out of (or because of) their social-structural roles, but instead are producing the recognizable features of being in a relationship, or being in a "with", as Goffman (1971, p.19-27) put it. Within discursive approaches, demonstrating the doing of a relationship is typically accomplished by examining the ways partners collaboratively produce particular actions that are said to 'pursue intimacy' or 'pursue controversy' (see Jefferson, Sacks, Schegloff, 1987; Hutchby, 1996), where such 'pursuits' are tractable through analyses of content alignment and stance affiliation.

In everyday relationships, speakers routinely monitor each other's talk for potential affiliatives and/or arguables and, when pursued, can be said to be 'doing relationship' by pursuing intimacy or pursuing controversy. Affiliation/controversy is seen as a practical achieved activity that is external and measurable, which involves speakers either displaying (or failing to display) coordination of stance or position (Conroy, 1999; Stivers, 2008). In drawing on Sacks's (1974) and Jefferson's (1978) work on how storytellers make relevant the taking of a stance by the recipient, Stivers (2008) has found that there is a preference for partners to align not simply with the content, but to also to affiliate with the stance or position of the teller. In response to a variety of discursive actions (i.e., story tellings, accounts, descriptions, evaluations, and preference disclosures), and particularly when sociorelational demands are high, speakers do relationships by working to affirm similar stances, and thus affiliate or pursue intimacy.

Discursive work on affiliation as a practical achieved activity has received wide attention. A range of research has focused on the affiliative and disaffiliative potential of certain actions, like questions/questioning (Steensig \& Drew, 2008), assessments (Ruusuvuori, 2005), and complaints (Drew \& Walker, 2009), to name a few. Clark, 
Drew, and Pinch (2003) have shown how salespersons elicit verbal expressions of affiliation from customers by reciprocating second-assessments which build on or repair customers own assessments. Drew and Walker (2009) have examined the disaffiliation that can result when a speaker goes too far in constructing a complainable on behalf of another, and of the resulting repair work needed to smooth out the disaffiliation. Waring (2005) has, similarly, also examined the production format of repair initiations as a vehicle for affiliation in graduate student seminars. Others have focused on the ways disaffiliation is repaired through specific discursive devices, like change of state tokens (Emmertsen and Heinemann, 2010) or amplitude shifts (Goldberg, 1978). Hutchby (1996) has detailed the ways talk-radio hosts monitor caller's accounts for potential arguables, and how hosts use a range of contrast-structures to proffer disaffiliation and thus pursue controversy.

The present study focuses on pursuits of intimacy that involve the use of improprieties in first encounters between previously unacquainted partners during speed-dating events. To date, research on speed-dating has largely been conducted in experimental social psychology, where the general focus has been showing that participants stated a priori mate preferences (on pre-event surveys) turn out to be poor predictors of mate-preferences on post-event surveys (see Eastwick \& Finkel, 2008; Finkel, Eastwick, \& Matthews, 2007; Fisman, Iyengar, Kamenica, \& Simonson, 2006; Houser, Horan, \& Furler, 2008). Unfortunately, the actual speed-dating interactions are typically treated as an experimental manipulation, and are often left unanalyzed (for critique, see Korobov, 2011a, 2011b; Stokoe, 2010b). This study aims to draw attention towards an analysis of the actual speed-dating interactions, to see the interaction itself as a social practice and to analyze it as the proper object of inquiry. A sequential-discursive perspective focuses on the ways social practices, like speed-dating interactions, are oriented to action and how those actions are co-constructed within unfolding sequential interaction.

Apropos for this inquiry, Jefferson, Sacks, and Schegloff (1987) showed how speakers pursue intimacy during expanded affiliative sequences where laughter was used to modulate improprieties (rudeness, obscenity, etc) at particular interactional tension mid-points to create affiliation. Jefferson and colleagues (1987) detail a wide range of responses to improprieties that range from rejection to enthusiastic affiliation, noting that recipients of improprieties typically begin by resisting it and then, in response to repeated offers, come to show appreciation and affiliation. Similarly, Glenn (2003) examined laughter in response to teases and other sexual improprieties, showing that potential interactional breaches in propriety may actually promote intimacy by building a flirtatious encounter. In Sacks (1978) discussion of dirty jokes, he notes that dirty jokes are recipient-designed objects that invite listeners to signal membership in the identity category that the impropriety indexes. Improprieties index culturally defined activities, rights, obligations, and predicates that are expected for members of certain relational categories. Within speed-dating interactions, improprieties can thus be seen as potentially relationally constructive, as they may allow speakers to display shared cultural understandings about being a romantic partner or being in a romantic partnership (see Mandelbaum 2003; Pomerantz and Mandelbaum 2005; Wilkinson and Kitzinger 2008). And, more specifically, improprieties may allow speakers to show themselves as a certain type of romantic partner or they may propose a distinct category of romantic partnership (Pomerantz and Mandelbaum 2005; Stokoe 2006, 2008, 2010a).

Consonant for the present study of speed-dating interactions, Glenn (2003, p. 156) speculates that improprieties may be particularly useful for intimacy pursuits in "courtship relevant interactions", where the relationship involves the possibility of romance, intimacy, or flirtation. Social scientists have noted that, for an increasingly confessional generation of young adults now saturated in webs of social-networking, being improper is tantamount to being candid; and that now, more than ever, it may be trendy to be candid-i.e., edgy, real, open, and disclosing (Chiou, 2006; Nosko, Wood, \& Molema, 2010; Weisbuch, Ivcevic, \& Ambady, 2009; Valkenburg \& Peter, 2009). Within discursive research, studies of the actual use of improprieties to pursue intimacy in live courtship-relevant interactions have received scant empirical attention. The present study uses a discursive approach to examine the ways improprieties are sequentially ordered to pursue intimacy, thus constituting part of the doing of initial relational fabric.

Although discursive work on speed-dating interactions is exceptionally rare, it is not without precedent. Using a discursive-conversation analytic approach, Stokoe (2010b) and Korobov (2011a, 2011b) have begun to systematically examine actual speed-dating interactions. Stokoe's (2010b) work focused on the reciprocal and sequential organization of speed dater's disclosures about their relationship histories and relational status, while Korobov's work focused on expanded affiliative sequences involving mate-preference disclosures (Korobov, 2011a), as well as the ways mate-preferences are often categorically gendered, and how reciprocal resistance to gender-conventional mate-preferences served as a preliminary for affective affiliation (Korobov, 2011b). 
Although there is some idea beforehand (see Stokoe, 2010b) of the topics that speed-daters tend to bring up, affiliative moments seem to emerge out of improvised intimacy pursuits that have distinct characteristics.

For example, Korobov (2011a) found that when speed-daters responded to their partner's mate-preference disclosures with inferentially elaborate probes (see Heritage, 1985; van der Houwen, 2009), which challenged the speaker to adopt a different or stronger version of their stated mate-preference (i.e., they were risky and potentially adversarial rejoinders), these probes actually promoted mutual affective stance affiliation. They created a playful environment of expansion around potentially troublesome inferences, which provided a mechanism for speed-daters to coordinate their stances. Korobov (2011b) also found that mate-preferences that were gendered in non-conventional ways also tended to function as a preliminary for affective affiliation. Resistance to gender conventionality allowed speed-daters to construct their identities in ways that appeared idiosyncratic or finely-tuned to their potential romantic partner-all interactive features which worked as preliminaries for affective affiliation.

The emerging idea here is that risky or non-conventional methods of self-presentation may, counterintuitively, work well for pursuing intimacy in initial courtship relevant interactions. Mandelbaum (2003) documents a similar phenomenon that she calls conversational 'tit-for-tat', describing it as an interactive method for constructing relationships whereby a speaker orients to a potentially problematic or non-normative activity, but in a reciprocal way, thereby rendering the potentially disjoining action as conjoining. Mandelbaum (2003) reveals how couples may engage in 'tit-for-tat' name-calling, which because of its reciprocal construction, is conjoining rather than adversarial. Jefferson and colleagues (1987) showed how speakers collaborate around the use of obscenity, and in so doing make covert proposals of intimacy. In short, potentially non-normative actions may allow members of potential romantic partnerships to stand out to one another and thus affiliate. The present study examines the ways collaborative resistance to conventional courtship relevant banter, concretized here in the form of couples' use of improprieties, works as an interactive method for potential romantic partners to pursue intimacy.

\section{Data and Method}

Speed-dating events come in all shapes and sizes. Although the ones that receive the most press are typically hosted by agencies at bars/restaurants, there are currently countless speed-dating events hosted for a variety of groups of people (gays and lesbians, Christians, book lovers, people with disabilities, etc) in a variety of settings (see Eastwick \& Finkel, 2008). Despite this heterogeneity, the current study was modeled around the relatively invariant features of most speed-dating events, which involve romantically available individuals attending an event where they participate in a series of uniformly short "dates" (e.g., 3 to 8 minute conversations) with other attendees. After the event, participants anonymously "yes" or "no" their dates; if two speed-daters "yes" one another, a "match" occurs and they are allowed to contact each other to presumably arrange a more traditional date. The data for the current study were derived from 72 speed-dates involving 24 participants (12 male; 12 female), with each date lasting approximately six minutes. All participants gave full consent to be recorded. Each of the 72 speed-dating conversations was audio recorded and transcribed according to Jefferson's (2004) transcription conventions.

Although the popular, agency-sponsored speed-dating events typically attract participants who are in their thirties and forties, many of which are divorcees with careers and children, the current project is part of a larger series of studies interested in initial romantic attraction in young adults (the focus on 'young adulthood' per se is not, however, part of the current study). As such, the data for the present study involve speed-dates from young adults. Initial recruitment began at a large university in the Southeast USA through word of mouth, posters, and emails. To be eligible to participate, all participants had to report being 'single' and 'currently interested in a romantic relationship'. We did not want a simulated speed-dating event. We wanted to create an actual event with participants that were genuinely motivated and interested in speed-dating. Because this particular university was known for hosting speed-dating events on Valentine's Day each year, many students were very familiar with speed-dating, and thus quite interested (all slots were filled within 48 hours). The resulting participant pool was a mixture of 19-24 year old university students and friends of university students from the local community.

The event was treated like an actual speed-dating event. The entire floor of a building was transformed into a lounge-like setting with small tables, chairs, and decorations. Many participants came dressed up. Drinks and food were provided. Participants were offered an explanation of what speed-dating was and how the six-minute conversations would work. The women remained seated while the men rotated every six minutes. Each participant carried a clipboard and would rate their dates with a "yes" or a "no". Following the event, all couples that matched would be notified through email, and given each other's contact information in order to pursue 
future dates. In sum, the current study aimed to create an ecologically relevant and self-contextualizing speed-dating context where sequences of talk exploring romantic possibilities would be common and relevant occurrences between unacquainted young adult potential romantic partners.

Since the focus is in the ways improprieties function in pursuits on intimacy, analysis began by culling from the data set all 'moments of improprieties'. Jefferson and colleagues' (1987, p. 160) broad definition of impropriety was adopted, i.e., that improprieties are "consequential, programmatic actions" that are "breaches (in) conversational standards of courtesy, propriety, tact, ethics, commonality, etc. etc., the breach in conventional standards at least potentially being offensive to other parties to the interaction." Although Jefferson and colleagues (1987) offer a broad list of improprieties (frankness, rudeness, crudeness, profanity, and obscenity), their project was not to systematically identify these types of improprieties, but to amass a collection of obvious exemplars and to then get on to what they see as the more important business of examining how these moments are produced and managed through laughter.

The present study began by using Jefferson and colleagues (1987) list of impropriety types (listed above) as a preliminary inductive coding guide to systematically identity the types of impropriety that emerged in the corpus of speed-dating conversations. Since there is arguably a massive difference between being 'frank' and being outright 'obscene', it was deemed important, at least initially, to document which forms of impropriety were most common as well as consequential for pursuing intimacy. After all, arguably different (and sometimes very different) identity relevant categories are indexed when one is 'frank' as opposed to outright 'obscene', suggesting that different improprieties may facilitate different types of intimacy pursuits. In sum, four types of impropriety were frequent enough to be systematically culled from the corpus. They were: 1) negative category attributions of non-present others (i.e., talking badly about others), 2) insults to the present conversational partner, 3) profanity, and 4) self-deprecation. The first two types, negative category attributions of non-present others and insults to the present conversational partner, were by far the most common and consequential forms of impropriety for pursuits of intimacy, and are thus the focus of the present analysis.

The following sequential discursive analyses focus on how these two forms of impropriety were formulated and consequential as preliminaries for intimacy pursuits. Discursive strategies for pursuing intimacy were identified with respect to each type of impropriety. First, with respect to negative category attributions of non-present others, nearly all formulations were about the category 'guys' or 'girls'. The recipients of such disclosures 1a) tended to orient to the negative attributions as if they themselves might be implicated, and would work to differentiate themselves from such categories of persons, which often resulted in affiliation. Or, secondly, 1b) recipients would escalate or upgrade the negative category attribution (see Jefferson et. al., 1987), thus establishing affiliation.

With respect to insults to the present conversational partner, the content of the insults tended to range widely, including insults about physical appearance, romantic preferences, or dispositional tendencies. The recipients of such insults surprisingly (but often) 2a) agreed with the insult, treating it not as adversarial, but rather as an indirect means of establishing repartee or as a flirtatious bid. Or, recipients would sometimes $2 \mathrm{~b}$ ) respond with an exaggerated or caricatured reaction to the insult, thus rendering it innocuous, which positioned the insulter as unserious and themselves as playful — all of which promoted affiliation/intimacy. The following analyses focus principally on the ways these response strategies to improprieties function as intimacy pursuits.

\section{Analysis}

\subsection{Pursuing Intimacy through Negative Category Attributions of Non-present Others}

Pursuits of intimacy often came on the heels of what closely resembles what Bergmann (1993) called "diversion gossip", i.e., negative talk about non-present others that tends to arise as a by-product of small-talk in non-structured settings between strangers or acquaintances. Such talk has a situational embeddedness to it, involves mutually known topics, and is generally accepted as a form of sociability. However, to avoid the potential stigma of such talk, and to instead use it as a means of establishing affiliation, the speed-daters in this study tended to use the following two discursive strategies to pursue intimacy.

\subsubsection{Pursuing Intimacy through Differentiation}

Differentiation involves formulating contrasts to categorical 'others' who are positioned as embodying attitudes, behaviors, or dispositions that define membership in a non-desired group. Such differentiation involves defining oneself negatively in contrastive 'not us' terms (see Stokoe, 2004; Widdicombe \& Wooffitt, 1995; Edley \& Wetherell, 1997). Showing how one does not possess certain critical categorical features can be a way of differentiating oneself or resisting membership in the social categories indexed by those features (Widdicombe 
\& Wooffitt, 1995). Resistance, however, is tricky, especially if the target category is one to which one of the speakers belongs. Resistance entails delicately undermining one's position with respect to those undesirable features through contrastive counter-claims (Speer \& Potter 2000; Stokoe, 2004). Such contrasts may have the effect of establishing oneself as a unique member of such a category. In these first two excerpts, the negative category attributions are formulated by the young men about 'women' and 'girls'; interestingly, the female speakers co-participate in the negative category construction, and both young women swiftly differentiate from such features near the tail end of each excerpt.

\section{(1) F6M4}

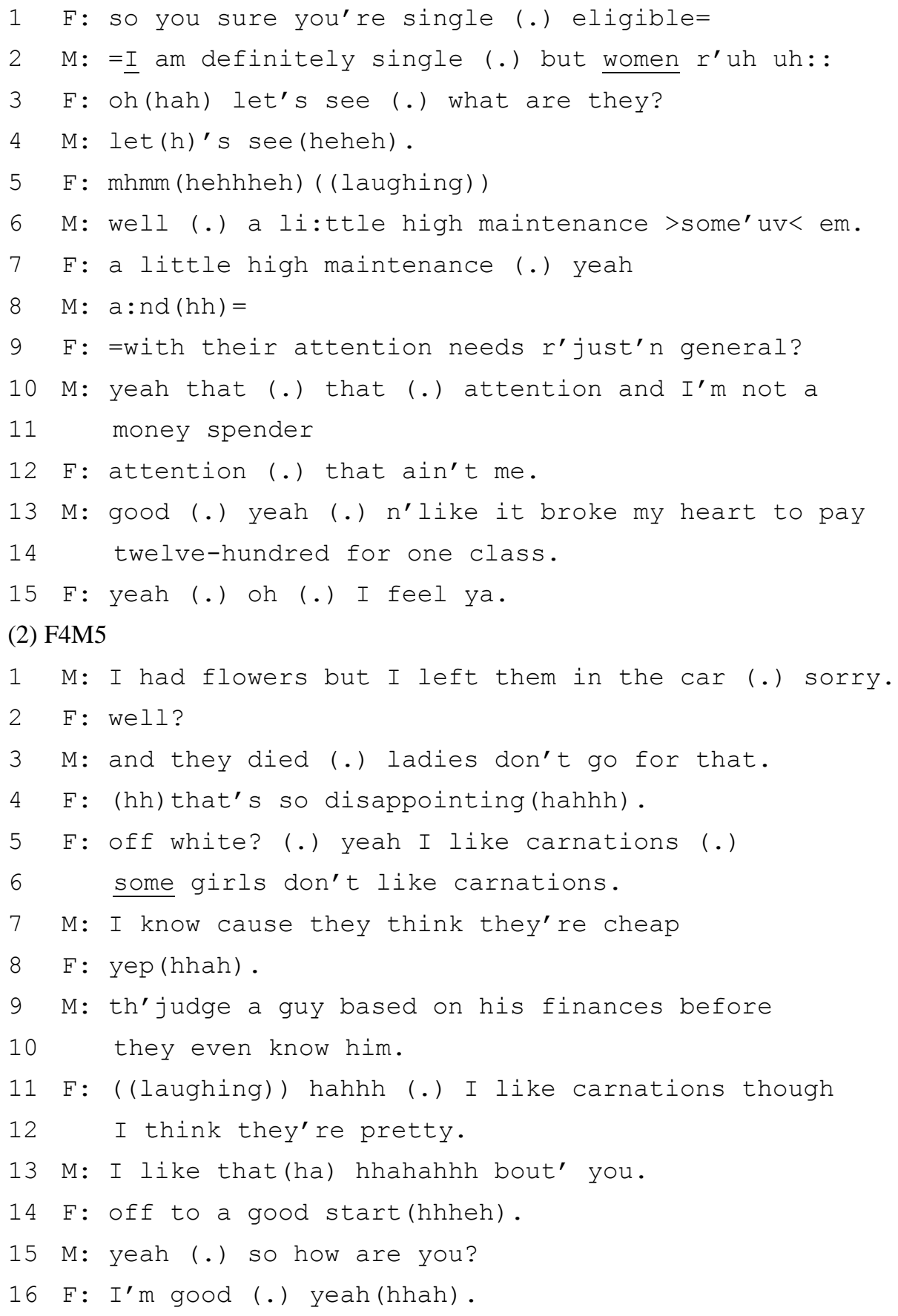

The above two excerpts reflect the most common pattern in the way negative category attributions (or NCA's) were formulated and managed. In each case, one speaker ( $\mathrm{M}$ in these examples) initiates an incomplete (hedged or mitigated) NCA (across lines 2, 4, and 6 in excerpt 1; across lines 1 and 3 in excerpt 2). The hedging and mitigation treat the NCA as delicate, thus attending to the subject-side and recipient-side risks (Edwards, 2005, 2007) of staging a complaint about a category to which one's interlocutor is a member. In response, the recipient 
(F in these examples) treats the NCA as an expected or incipient topic (line 3 in excerpt 1; lines 4-5 in excerpt 2). F orients to it not only as an expected action, but goes further by demonstrating knowledge about the NCA, thus co-developing it topically, doing so with intermittent laughter (see Jefferson et. al, 1987) which constructs it as non-serious, thus showing that she is not seriously implicated by the NCA (lines 7 and 9 in excerpt 1; lines 5-6 and 8 in excerpt 2). F's co-participation in topic expansion and levity work as a preliminary for M to further develop the NCA in a less mitigated and more inoculated way (line 10 in excerpt 1; lines 7 and 9 in excerpt 2), where both speakers begin to appear to be in sync around it. F then constructs a swift and succinct formulation of contrast, or differentiation, from the negative features of the co-constructed category (line 12 in excerpt 1; lines 11-12 in excerpt 2). $M$ then appreciates the differentiation, and both signal affective affiliation, thus pursuing intimacy, across the final turns. This 5-step pattern could be represented as:

\section{Speaker A initiates a hedged/mitigated NCA}

2. Speaker B treats the NCA as an incipient action, displays knowledge about it, and co-constructs the NCA using laughter

3. Speaker A expands the NCA in a less mitigated way, thus aligning with B.

4. Speaker B differentiates from the NCA

5. Speaker A appreciates the differentiation and both engage in affiliation

Although the above pattern was the most common method for differentiating from NCA's, speakers would sometimes formulate NCA's about their own category and then differentiate from such features. In the next excerpt, F occasions and then resists the undesirable features of a certain type of woman ('complaining', 'moaning', 'naggin'). She does so by imagining these negative features in a female that M might prefer, and then jokingly solicits collusion from $\mathrm{M}$ in rejecting such features, thus pursuing intimacy.

(3) (F6M1)

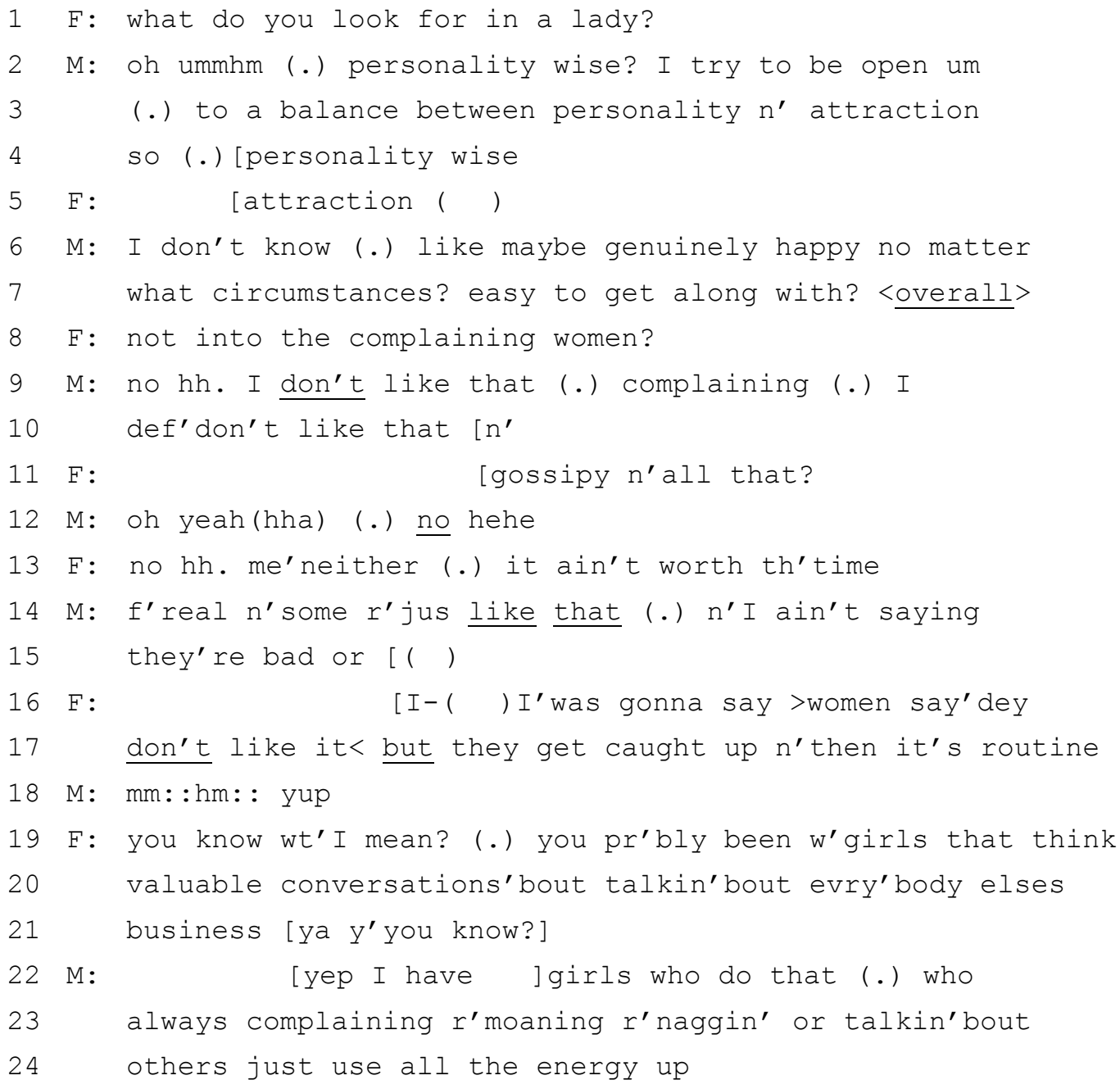




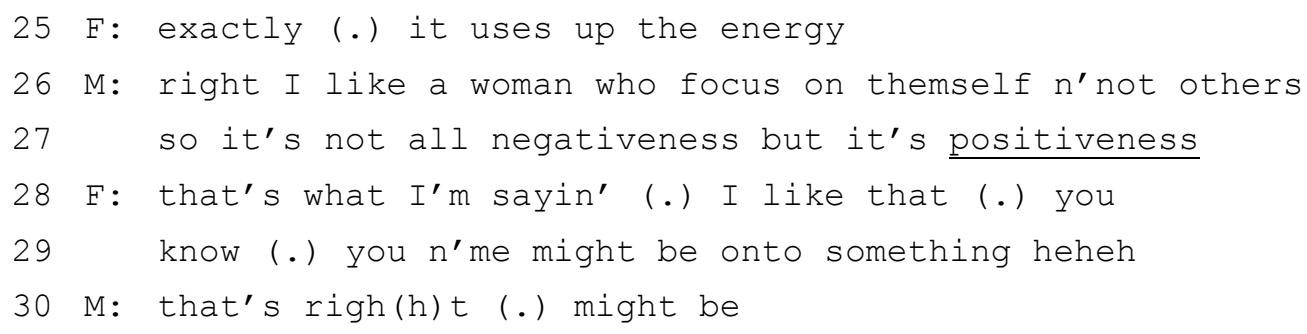

F's first two self-selected NCA's come in lines 8 ('not into the complaining women?') and 11 ('gossipy n'all that?') as contrasts to the type of personality type M prefers ('genuinely happy' and 'easy to get along with'). That F's receipt is a jocular imagining of a contrast rather than a recycling or proffering of M's stated formulation is action-orienting. It treats M's preference as a potentially euphemistic non-statement about disinterest in 'complaining' or 'gossipy' type women. This creates the potential for interactive trouble were M to straightforwardly agree, since agreeing that he is disinterested in 'complaining' and 'gossipy' types may perpetuate stereotypical or sexist views of women, thus damaging the subject-side of M's self-presentation. However, because F's probes are built with a casual turn-initial solicitation ('not into the...'), and because they are about broad and scripted categories of undesirable features ('complainers', 'gossipy n'all'), they prefer a 'no' answer, with their extremity inoculating against any damage agreement might do. And because these features are extreme, they enable $M$ to affiliate with F's inference while not appearing to be the source of the inference, which he does through repetition ('I don't like that (.) complaining') and escalation ('I def'don't like that'). By line 13, the tables have turned-F displays affiliation with $\mathrm{M}$ ('me'neither') towards a stance she originally elicited from M through her own indirect resistance to her self-initiated NCA's.

After some coordinated topic expansion about undesirable scripted female features (lines 14-18), F once again (lines 19-21) indirectly resists categorical attributions by suggesting that $M$ has probably been with girls that have these undesirable qualities. Like in the first part of this excerpt, $\mathrm{M}$ does not orient to this conjecture as a criticism or stance disaffiliating provocation, but instead treats it as a preliminary for collusion around a familiarity ("yep I have") and a mutual dissatisfaction for these types of women who "just use all the energy up". $\mathrm{M}$ and $\mathrm{F}$ are able to affiliate through coordinated resistance; $\mathrm{F}$ resists appearing to be the type of female $\mathrm{M}$ is disinterested in. F positions $\mathrm{M}$ as having the kind of knowledge she has, that is, up-close experiential knowledge about what is unhealthy. Orienting to him this way effectively positions them as co-members of the same gendered mate-preference category. $\mathrm{M}$ signals alignment through agreement, topic expansion, and escalation (lines 22-27), after which she is then able to display affiliation ("that's what I'm sayin"' and "you n'me might be onto something") towards $\mathrm{M}$ about a stance she originally solicited with her indirect resistance to what are treated as common or normative female qualities. There is an elegant orchestration here with respect to way their coordinated resistance results in affective stance affiliation.

In some cases, a speed-dater would capitalize on a self-deprecating admission from their interlocutor and position the speaker's personal admission as a reflection of a NCA. Interestingly, moves like this rarely resulted in interactive trouble, but rather were taken up in ways that promoted affiliation. In the following example, F positions M's self-confessed pickiness about women as a breach in what would normatively be expected from 'guys'. M then differentiates from the type of 'guy' implicated by F's positioning while preserving affiliation with her.

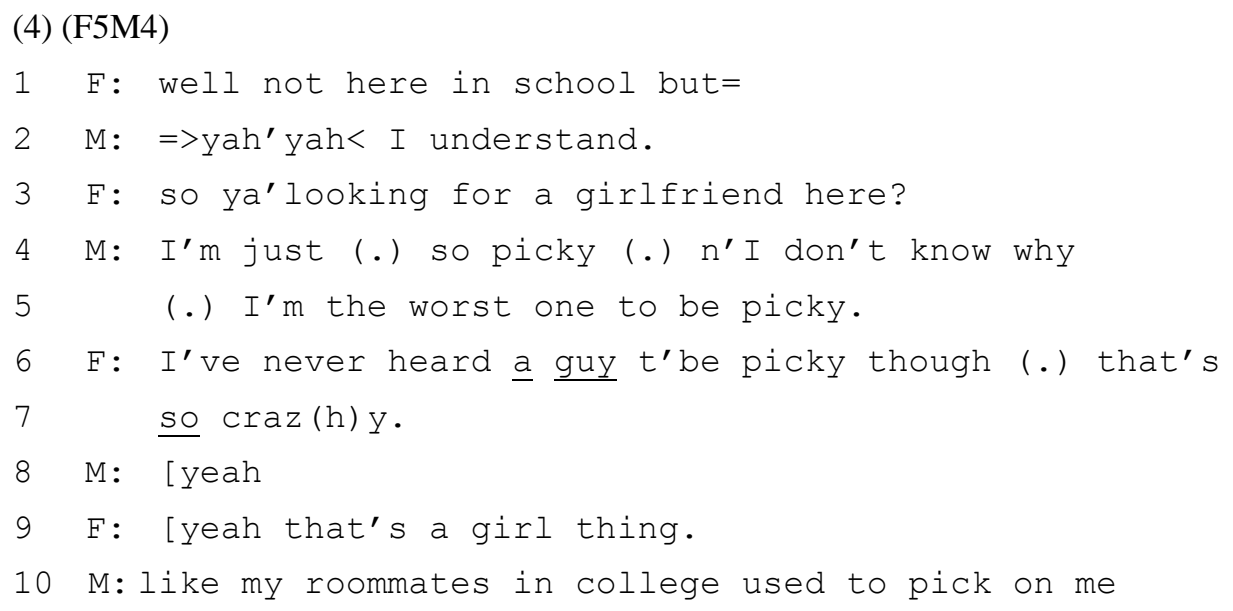




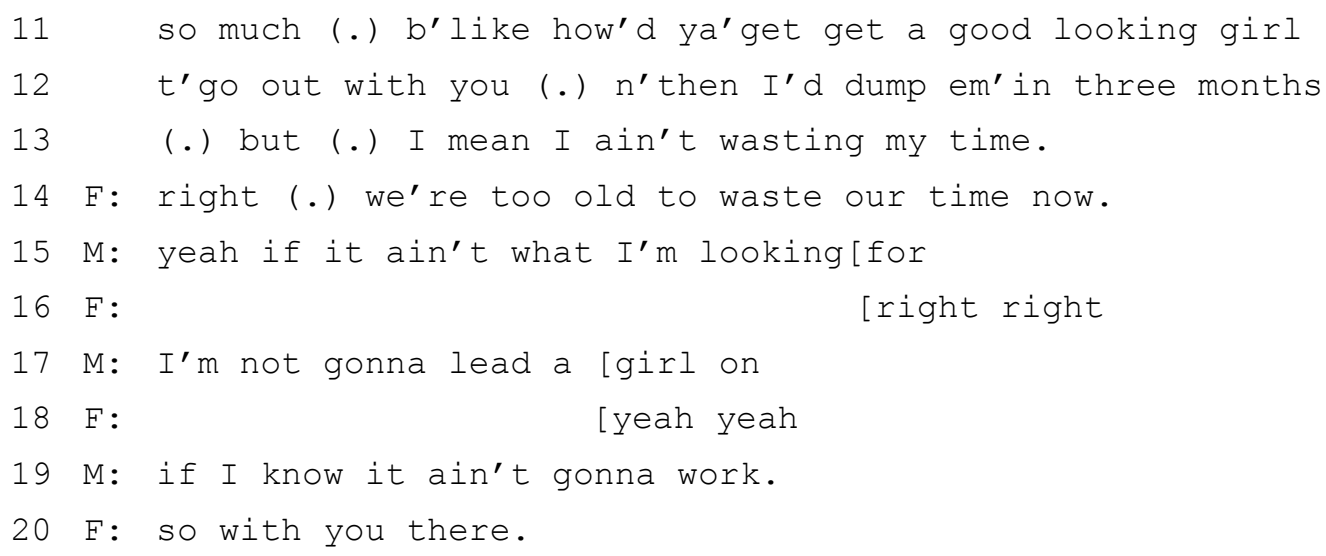

M's initial receipt of F's topic proffer is to position himself as 'picky', and to then problematize that formulation with a display of uncertainty ('n'I don't know why') and self-deprecation ('I'm the worst one to be picky'). The display of uncertainty and self-deprecation is recipient oriented-it attends to, and perhaps mitigates, the potential interactional trouble of coming off as 'picky' to a potential romantic partner. In other words, his admission anticipates negative uptake. Although in many instances self-deprecation prefers disagreement (see Pomerantz, 1978), in this particular exchange F's initial receipt is not disagreement. What she attends to is not his evaluation of his pickiness, but rather is the fact of his pickiness as a member of the category 'guy'. F's evaluation is not about his individual pickiness, but is a scripted NCA that the pickiness of any 'guy' is out of the realm of normalcy ('I've never heard') and is generally and psychologically aberrant ('that's so crazy'). Not only is it non-normative for 'guys', but it is 'a girl thing'.

$\mathrm{M}$ is left to attend to two discursive tasks. First, he must realign himself with some activity which inscribes him back into the category 'guy'. And second, since 'pickiness' is a 'girl thing', he must offer an account for his 'pickiness' that is stance affiliating. M's differentiation process begins by first expanding his regular action pattern to involve not simply being routinely picky, but also to being someone who routinely 'gets a good looking girl' and then 'dumps them', where getting attractive females and disposing of them are arguably dispositional action patterns that index what might be stereotypically expected from 'guys'. To account for being picky, M claims that it results from a superordinate dispositional commitment to not 'wasting time', or 'not leading a girl on'. His pickiness thus comes off as a mark of relational integrity, not 'girliness', to which F expresses affective alignment and affiliation (lines 16, 18,20). Note the elegant orchestration here: M's initial receipt (lines 4-5) of F's topic proffer has the effect of eliciting from $\mathrm{F}$ a positioning of $\mathrm{M}$ as a guy who is resistant to gender conventionality. Although risky, F's receipt opens a space for $\mathrm{M}$ to offer an expanded gender-relevant account of himself that simultaneously reclaims membership into category 'guy' (it is thus face-saving) while nevertheless providing something novel and idiosyncratic, which is an account for his resistance that functions as a preliminary for interpersonal alignment and affiliation.

\subsubsection{Pursuing Intimacy by Escalating NCA's}

A second method for orienting to NCA's as preliminaries for intimacy pursuits was to escalate the negative category attribution. Rather than differentiating from self-implicating NCA's, some speakers would escalate or upgrade the undesirable features of the NCA in a way that systematically solicited alignment and affiliation from their interlocutor (see Jefferson et. al., 1987). Interestingly, in the majority of these cases, the speaker who occasions the NCA is a member of the category that is negatively implicated by the NCA. In the two excerpts below, F occasions NCA's about the category 'girls', and rather than straight-forwardly differentiating from them, she recruits appreciation and alignment from $\mathrm{M}$ and, with modulating laughter (see Jefferson et. al., 1987), escalates the NCA, thereby pursuing intimacy with M.

\section{(5) (F5M2)}

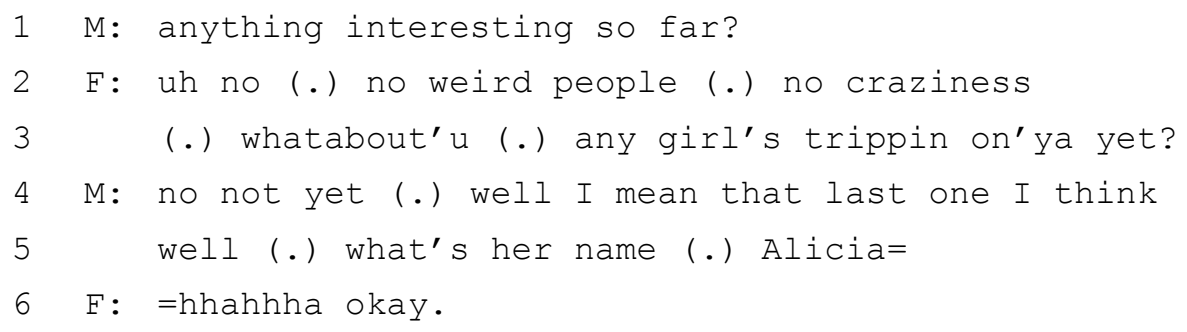




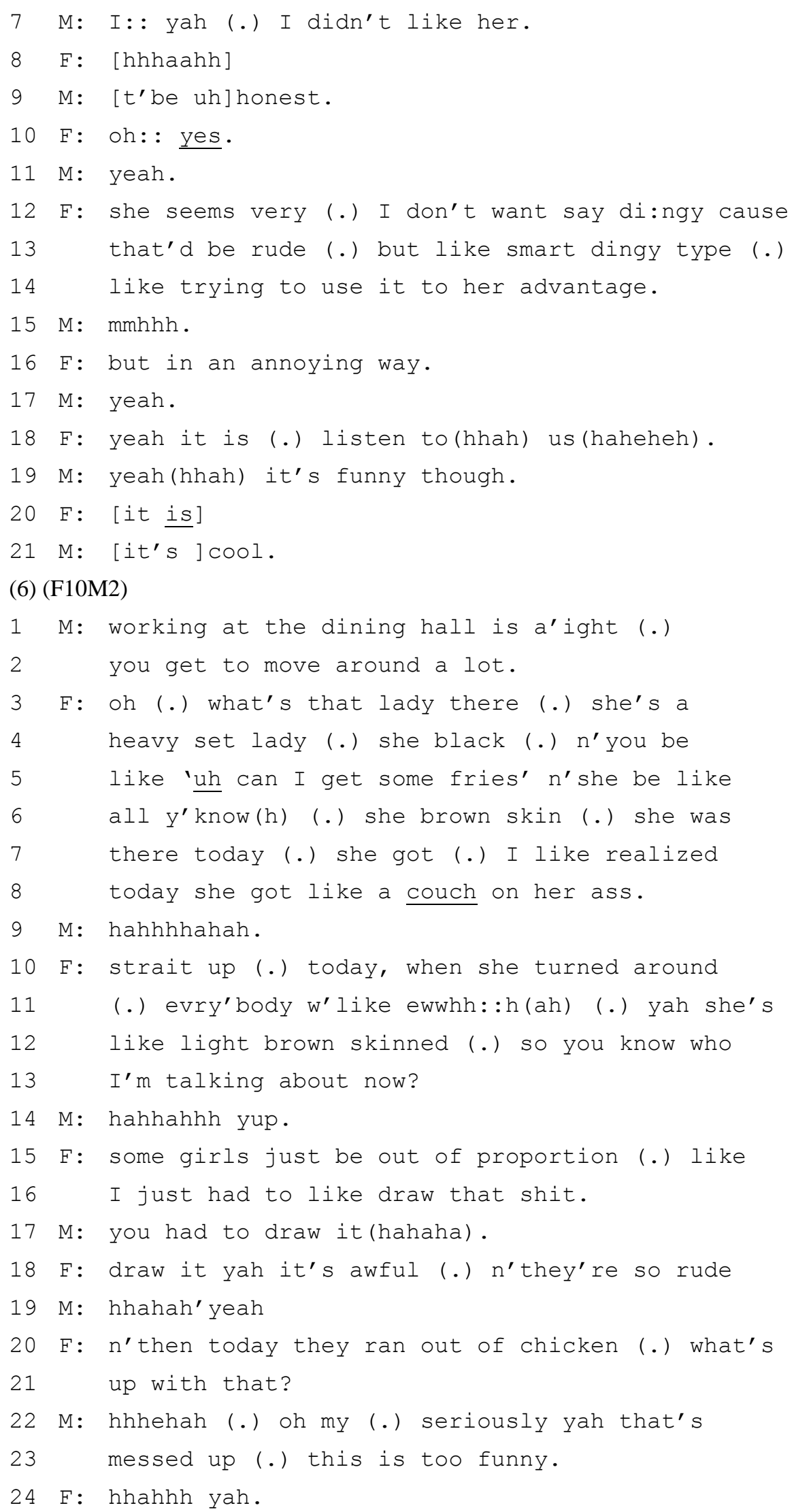

Like the first two excerpts, excerpts 5 and 6 reflect a pattern common in examples where intimacy pursuits are accomplished by escalating NCA's. In each of the excerpts above, one speaker (F in both cases) occasions an NCA about 'girls' (in line 3 in excerpt 5; in line 15 in excerpt 6, where lines 1-14 involve an extended preface 
where, before occasioning the general category 'girls', F mocks a particular female cafeteria worker). M then affiliates with F's NCA, but in both cases does so delicately -in excerpt 5, by using hedges, displays of uncertainty, and doing being honest (lines $4-5,7,9$ ); in excerpt 6 , by simply replicating the NCA with laughter (line 17). M thus attends to the subject-side risks (Edwards, 2005, 2007) of direct agreement with a criticism of a categorical class of people to which his interlocutor is an ostensible member. In response, F escalates the NCA (in lines 12-14 and 16 in excerpt 5; in line 18 and 20 in excerpt 6). In both cases, the escalation solicits alignment and affiliation from $\mathrm{M}$, as well as an appreciation (from both $\mathrm{M}$ and $\mathrm{F}$ ) for the general type of social action they are engaged in (lines 17-21 in excerpt 5; lines 19-24 in excerpt 6). The pattern is:

1. Speaker A occasions a NCA

2. Speaker B affiliates with the NCA, but in a mitigated way.

3. Speaker A escalates the NCA

4. Speaker B aligns and affiliates with speaker A's escalation; both speakers then pursue intimacy through additional agreement, laughter, and agreement about their social activity.

\subsection{Pursuing Intimacy through Insults to the Present Conversational Partner}

Insults are typically treated as a special, and potentially more aggressive (than, say, sarcasm or irony) form of 'disparagement humor' (Janes \& Olsen, 2000). Insults involve characterizations of a recipient as defective in some socially relevant way (Goodwin, 1990), or may involve disparaging comments about a person's behavior, possessions, preferences, or appearance (Evaldsson, 2005). Insults have been historically studied in the form of ritualized insults or verbal dueling, where speakers engage in a tic-for-tac style of insulting (playfully or seriously), turning insults against one another in an attempt to outperform the other or otherwise have the last word/laugh (see Abraham, 1974, Kochman, 1983, Rampton, 1995). The insults in this corpus were not of this kind; in fact, quite the opposite, the insults were not preliminaries for duels or games of one-upsmanship. Rather, they worked more like flirtatious bids. Apropos for this approach to insults, Evaldsson (2005) has found that in contexts where there is a press for relationality, recipients of insults often stage counters to the insults, but would do so in ways that transformed the insult from being adversarial to being fodder for building solidarity through a shared transgression of socio-relational norms. Insults, in this way, function as discursive resources for pursing intimacy. In the present study, the insults that resulted in affiliation were insults that were directed to the other person present. These insults usually resulted in affiliation, as the recipient of the insult would either agree straightaway with it, thus treating it as obvious and known, or else would construct an exaggerated response to it.

\subsubsection{Pursuing Intimacy by Agreeing with the Insult}

This first excerpt opens midway through a discussion of M talking about enjoying going to see movies on dates. In line 1, he opens with a disclaimer that positions his forthcoming admission as unconventional- that is, that (potentially) unlike most people, he does not enjoy discussing the movie afterwards but would rather 'think' about it. This occasions an insult from $\mathrm{F}$ in line 6.

\section{(7)(M2F11)}

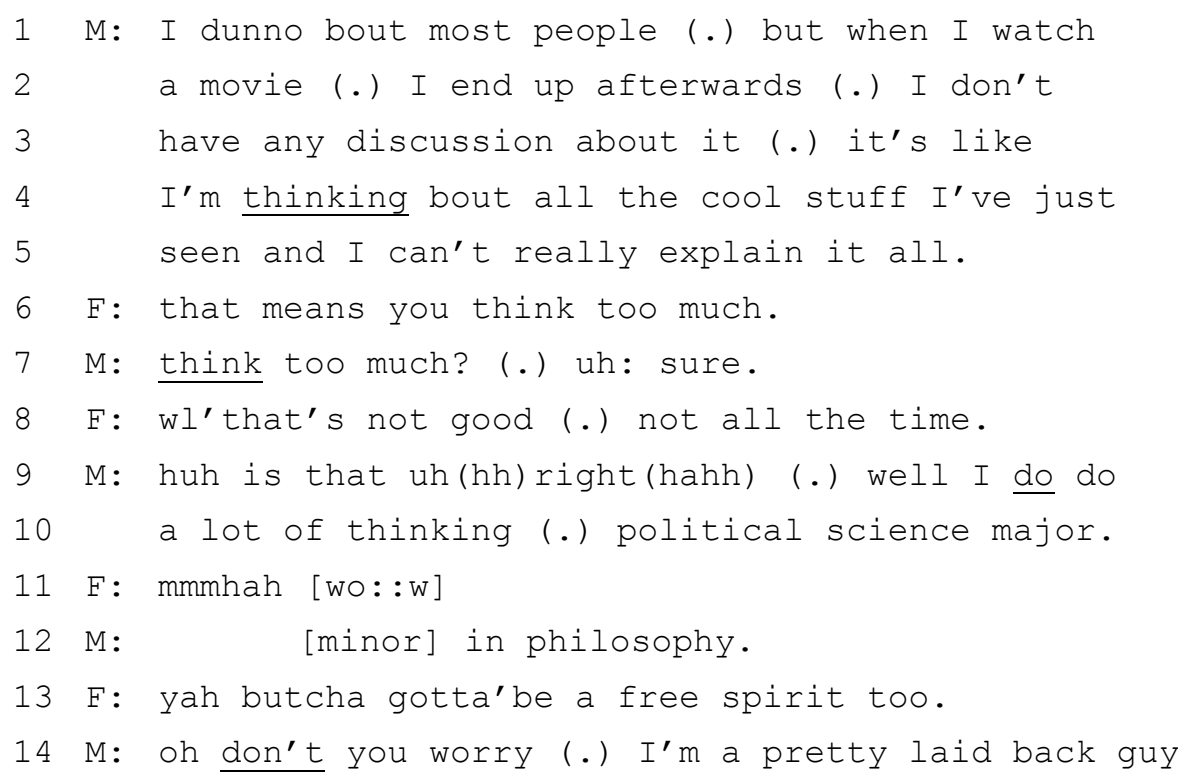




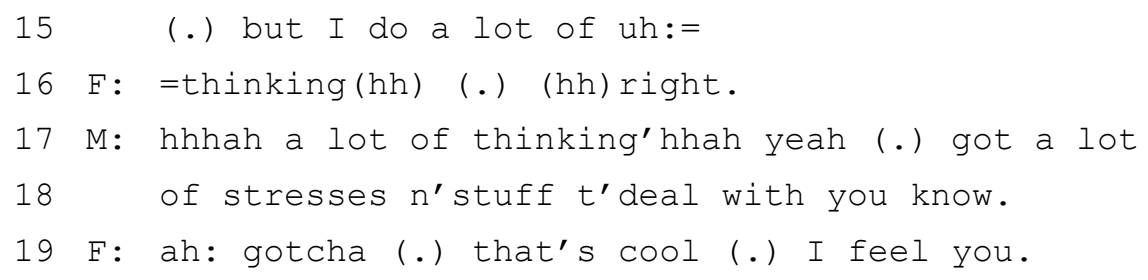

F's insult ("that means you think too much") works as a quick and reductive encapsulation of M's stated preference, a preference initially hedged with a disclaimer that shows his understanding of its potential unconventionality, and an admission of a disability ("I can't really explain it all"). F's insult is thus rife with the potential for interactive trouble. Interestingly, however, in this corpus of speed-dating conversations, fast and loose insult retorts were common, and were rarely taken up as serious or adversarial. M's initial response in line 7 is a simple repetition with questioning intonation, which selects and, by questioning it, problematizes the action F is engaged in. His tag of "uh: sure" is a sine dicendo rhetorical response, which displays agreement with F's characterization, but not simple agreement. The "uh: sure" treats her characterization as an obvious and thus benign sort of observation, which weakens it.

This occasions an upgrade from F in line 8 ("wl'that's not good"), but also a softener ("not all the time") that particularizes the problematic behavior as being not good only some of the time. In line 9 , M formulates the idiomatic "is that right?" rejoinder, which again problematizes and undermines her critique; but note, however, that he formulates this with a laughed through delivery, which positions F's critique (and his uptake of it) as unserious. He follows this up (lines 9-10) by agreeing yet again that he does do a lot of thinking, justifying it by positioning himself as belonging to a certain identity category of thinking people (political science majors and philosophy minors). In line 11, F displays a token of exaggerated surprise ("wo::w"), but does so by recycling the laughter frame, which characterizes her surprise as feigned or playful and not as a sign that she is genuinely impressed. By line 12, there is an obviously playful repartee developing, despite the insults by $\mathrm{F}$, and the immobilization of them by M's sine dicendo rhetorical responses, agreement, and rationalization.

In line 13, F uses the idiomatic "yah but" formulation to extend yet again the insult ("yah butcha gotta"be a free spirit too"). In line 14, M responds with the common 'oh' change of state token (Heritage, 1984), which works here as a way of counterinforming, with the idiomatic 'don't you worry' follow-up working to position $\mathrm{F}$ as overly (or unnecessarily) concerned, which again undermines her insult. This change of state and idiomatic phrase sets up agreement yet again from $\mathrm{M}$, but now as someone who is a part of the identity category "laid back guy". With laughter, F completes M's turn by recycling and focalizes on the selected item "thinking" (line 16), to which M laughingly agrees yet again (line 17). The agreement is once again prefatory, as M goes on to account for his predilection for 'thinking a lot' by appealing to his life circumstances ("got a lot of stresses n'stuff t'deal with"). M's tag of "you know" is a common knowledge component (see Stokoe, 2010a) that proposes that the two speakers share knowledge about an extant social/cultural order (that it may be normal to think a lot when one has stress and stuff to deal with). It thus fishes for affiliation. In the final line, F not only displays understanding, but also affective affiliation.

In this next excerpt, $\mathrm{M}$ positions $\mathrm{F}$ as a certain type of female that may prefer a partner who 'spoils' her, where desiring to be spoiled could be heard as an insult.

(8)(F2M2)

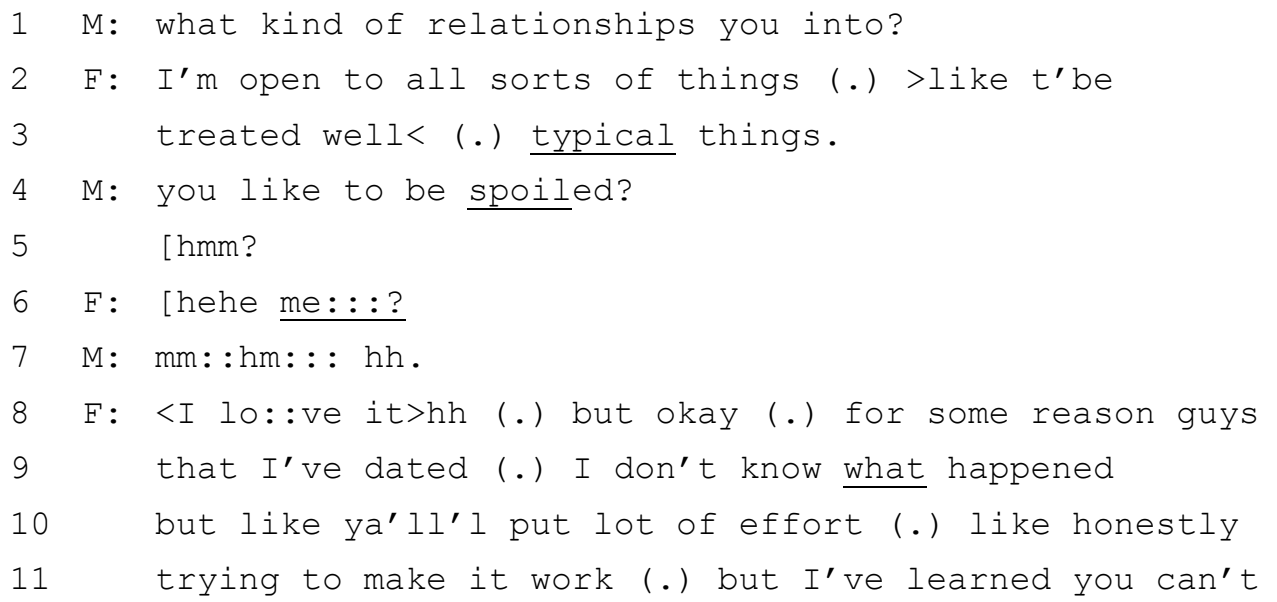




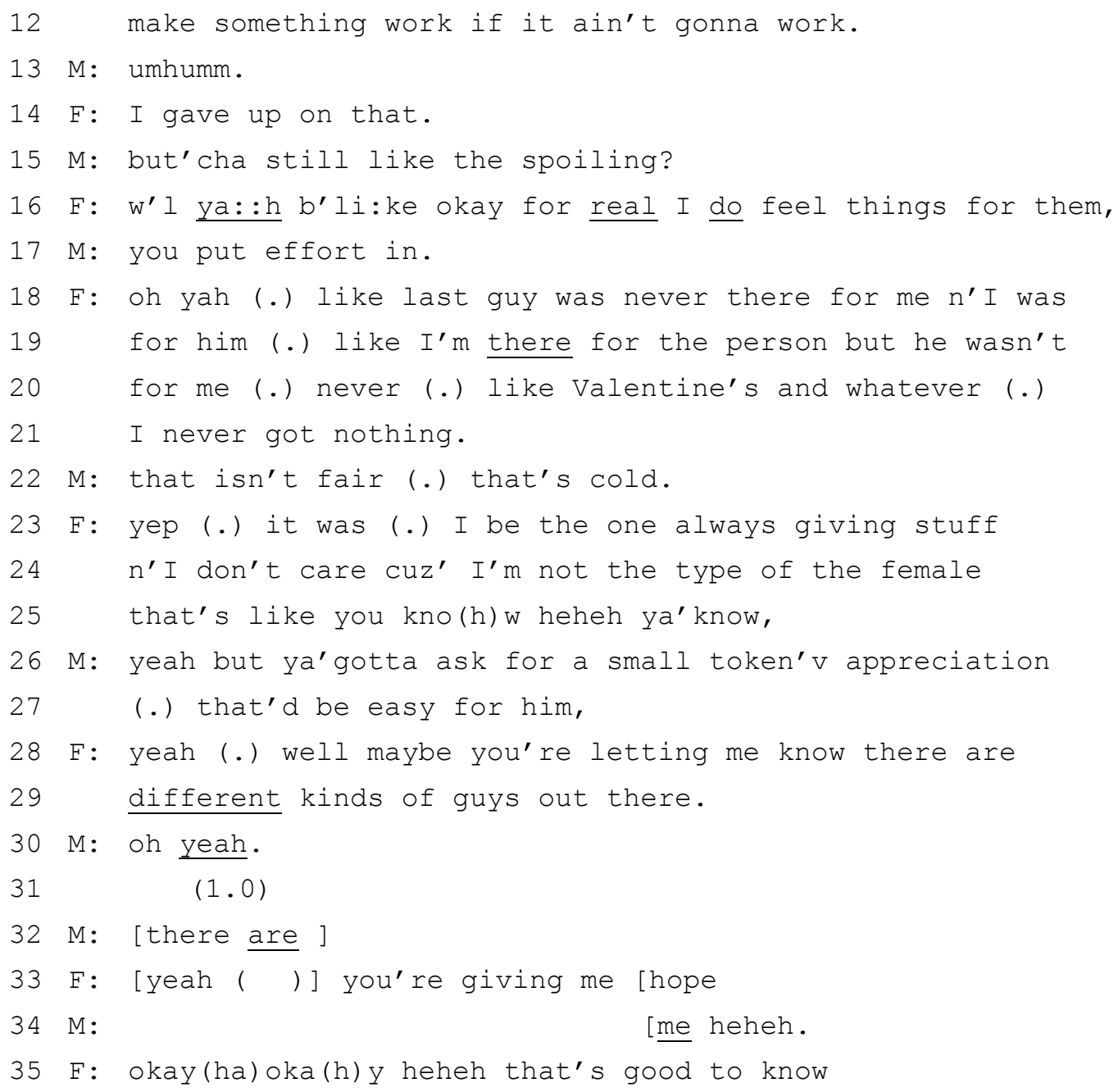

F's initial "like t'be treated well" is reinterpreted by M as a euphemism for 'liking to be spoiled', which comes off as a gender-relevant insult that has negative dispositional implications for F. Yet, instead of orienting to it as an insult, $\mathrm{F}$ laughs and displays a knowing and exaggerated surprise ("me:::?"), thus treating the insult as a playful provocation. M shapes his reply in kind by recycling F's elongated affect with an exaggerated smile voice agreement of "mm::hm:::", which F parallels with the staged agreement of " $<\mathrm{I}$ lo::ve it $>$ hh". In effect, M's bid to position $\mathrm{F}$ within an undesirable category of females occasions a three-part repartee: $\mathrm{F}$ appears playfully coy, $\mathrm{M}$ appears playfully suspicious, and $\mathrm{F}$ agrees and appears playfully honest.

F's "but okay" in line 8 both acknowledges the play frame and breaks with it. She shifts towards a focus on 'guys' who try too hard when the relationship is not working, to which M responds by recycling the insult "but'cha still like the spoiling". His recycling avoids F's shift of focus onto 'guys' and thus holds her accountable to the possibility that she knowingly takes advantage of her partner's generosity. The opening part of F's response in line 16 ("w'l ya::h") is another sine dicendo rhetorical response that treats his question as having an obvious answer, and proceeds to select that obvious answer. By positioning it as obvious, she inoculates it from its ability to make her preference seem aberrant. Its obviousness thus does subject-side work (Edwards 2005, 2007), but also does interactive work; it positions the two of them as sharing obvious knowledge. Like her turn in line 8, it is after a jocular rejoinder that she turns to the second part of her turn to deflect possible negative inferences. Following this, M's next contribution in line 17 ("you put effort in") does not further continue the insults, but instead states the implication of her prior statement that she feels things for her partners, which negates his claim in line 15 that suggested she might be manipulative. By line 17, the two appear in sync, despite the riskiness of M's insulting, negative dispositional scripting of $\mathrm{F}$.

Lines 18-25 are topic expansive, with $\mathrm{F}$ providing a relational history account where her generosity and support were freely given but unreciprocated by her last male partner. Although $\mathrm{M}$ aligns with her stance in line 22, which promotes topic expansion, he proposes closure to her relational history account by again positioning her as potentially complicit with gender-conventionality with "but ya' gotta ask for a small token'v appreciation". This 
suggestion is hearable as yet another insult. He adds that such appreciation would be 'easy' for her partner to show. The potentially negative dispositional inference/insult here is that F may fit the category of being overly 'docile' or 'passive' because she cannot or will not ask for what she wants, when what she wants is an 'easy' thing for her partner to give. Like with M's previous insulting insinuations, F does not treat this as a criticism, but rather treats it as a presentation of alternative possibilities-i.e., as a way that $\mathrm{M}$ is letting her know that there are different kinds of guys available. Given the speed-dating context, F's response positions M as perhaps having a stake or interest (Edwards \& Potter, 1992) in making such an observation. In short, F's response treats M's negative categorical scripting of $\mathrm{F}$ not as a genuine insult, but as a method by which $\mathrm{M}$ is signaling that he may be one such alternative possibility (a possibility ratified by M in line 34). F thus orients to M's provocations as flirtatious bids, which are made plain across the final turns of the excerpt.

\subsubsection{Pursuing Intimacy through Exaggerated Responses to the Insult}

The use of exaggeration or caricature as a response strategy to insults (or negative category attributions) has been documented by Rampton $(1995,1999)$ in his work on 'linguistic crossing' and 'stylisation', and Georgakopoulou (2002) in her sociolinguistic work on the discursive strategies used to construct gender in Greek youth subcultures. Rampton (1999) has noted the ways that speakers will 'style the other' either by literally caricaturing their voices (recycling comments with distorted intonation) or, as was the case in the current data, by formulating an asymmetrical affective overreaction, which in the context of responses to insults, positions the insult as absurd. In the present corpus of data, recipients of insults would often respond with an exaggerated or caricatured reaction to the insult, thus treating the insult as innocuous. This worked to position the insulter as non-aggressive and the recipient as playfully receptive, both working to promote an environment ripe for affiliation/intimacy.

The first excerpt takes place immediately as the speed-date begins. $\mathrm{F}$ has just sat down. As the dialogue begins, $\mathrm{F}$ is in the process of circling 'yes' or 'no' about her previous speed-date. Her insult comes in line 2 as she asks M if he is watching her make her selection, accusing him of being afraid of rejection.

(9)(M2F9)

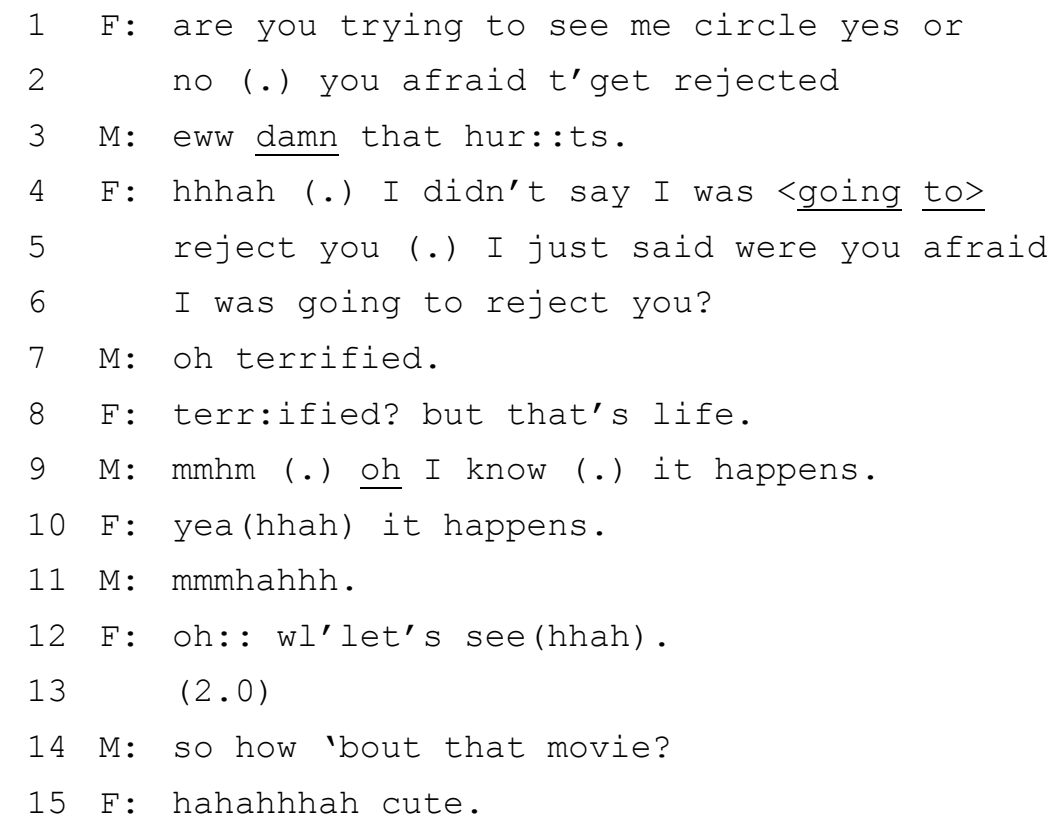

F's insult is unmitigated, as there is no laughter or smile-voice or any paralinguistic cues that would suggest playfulness. Yet, because there is very little that $\mathrm{M}$ has done to implicate himself as fearful of rejection (other than perhaps glancing at her clipboard), and because the speed-date is a staged activity, there is plenty of space for $\mathrm{M}$ to shape a response that rejects F's action as being genuinely hostile or insulting. He does so with a two-part exaggerated reply in line 3 that first involves a colloquial affective component ("eww damn") with phatic emphasis and then an exaggeration formulation of personal woundedness ("that hur::ts"). F's initial receipt of laughter in line 4 ratifies and affectively affiliates with M's jocular, non-serious interpretation of F's insult. $\mathrm{F}$ then attends to the subject side risks of formulating an insult, clarifying that she was merely asking if $\mathrm{M}$ was afraid rather than implying he was afraid. This is face-saving for both of them, protecting her from appearing to be making an accusation and him from signaling anything overt that would be evidence of fear. His 
reply in line 7, even after her softening clarification, is once again an exaggerated caricature of his fear. She replies (line 8 ) by using elongated intonation in recycling and thus exaggerating the lexical item "terrified", but formulates it as a question and, in using the iterative present tense to do so, normalizes the general experience of being rejected in life. $\mathrm{M}$ then affiliates with $\mathrm{F}$, agreeing that rejection happens, and thus displays that they are both in sync with respect to their understanding of the social action they are cooperatively engaged in. With laughter, F agrees (line 10), to which $\mathrm{M}$ (line 11) responds with laughter.

From lines 12-15, the play frame is extended and deepened. Playing up the vagueness and innuendo of "it happens" (in line 9 and then recycled again in line 10), F couples the change of state token "oh::" (with elongated phatic intonation) with the idiomatic (and affiliative) "let us see" formulation with terminal laughter to playfully imagine whether rejection (or, by extension/implication, acceptance) will happen between her and $\mathrm{M}$ (line 12). M's phrasing is key, as it effectively positions $\mathrm{M}$ and $\mathrm{F}$ as a potential romantic couple. It occasions the possibility of intimacy, and could thus be considered to be a pursuit of intimacy. The pregnant pause in line 13 underscores the potential delicacy of such an intimacy pursuit. M's delayed rejoinder in line 14 ("so how "bout that movie?") is the kind of idiomatic formulation that playfully is the ostensible performance of doing of being uncomfortable, which ratifies the possibility of seeing F's turn in line 12 as indeed an intimacy pursuit of sorts. To put it colloquially, $\mathrm{M}$ and $\mathrm{F}$ are jointly displaying a comfortably uncomfortable affiliative position. In the final turn, F appreciates ("hahahhhah") and then affiliates ("cute") with M's stance.

The next except also begins near the start of the speed-date. M's insult comes in line 8, as he positions $\mathrm{F}$ as potentially promiscuous. F's exaggerated and upgraded response follows in line 9.

(10)(M5F4)

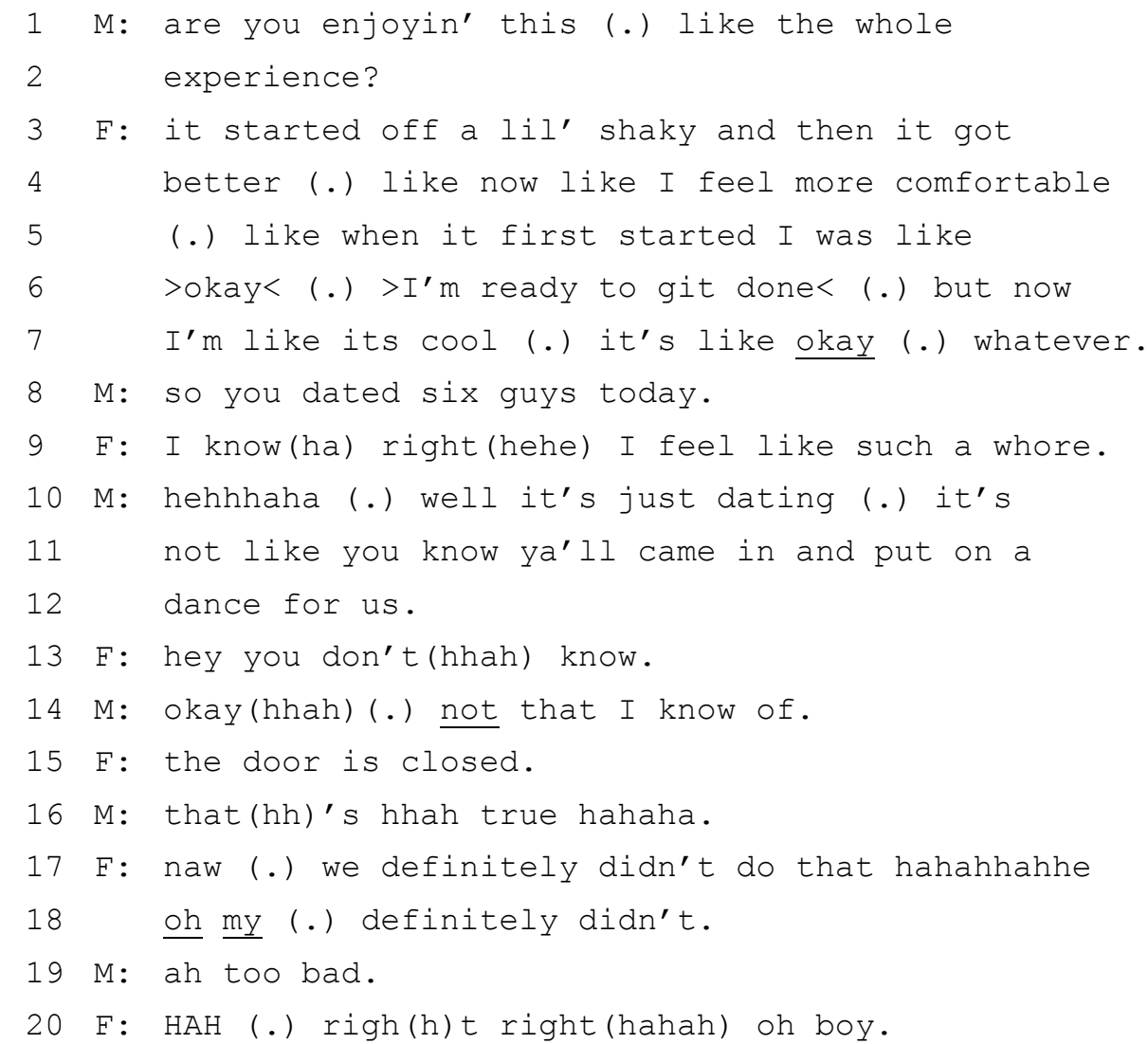

Like in the prior excerpt, M's insult in line 8 is unmitigated, as there is no laughter or smile-voice or any paralinguistic cues that would suggest playfulness. Even M's turn-initial "so" indexes a kind of incipient action (see Bolden, 2008), suggesting that a noticing of this sort may be an expected action in such an environment. The sort of noticing that it is, however, is what matters. M's noticing effaces the context, i.e., that the six dates in one day were all extremely short, non-sexual speed-dates (that he additionally fails to mention that he also participated in); as such, his insult, incipient as it may be, is designed with the option to be taken up as a non-serious tease. In the turn following (line 9), F takes it up as such, as she agrees by producing two consecutive agreement-plus-laughter formulations; interestingly, though, she does more than agree. She goes on 
to exaggerate/upgrade M's implied insult by positioning herself vis-à-vis the identity category "whore" in "I feel like such a whore".

$\mathrm{M}$ then displays alignment through immediate laughter, but not quite affiliation, as he begins with the turn-initial preface of "well" in "well it's just dating". Turn initial components such as "well" have been shown to project disagreement (see Pomerantz, 1984), showing that perhaps F has gone too far. M's softens the implications of F's categorical self-positioning in noting that "it's just speed dating" (an important move for recognizing the non-seriousness of her self-positioning), but goes on to collude (and thus affiliate) with the sexualized play frame indexed by "whore". He does so by imagining the presence of an absence - that is, he imagines a scripted action pattern (see Edwards, 1995) of her and the other women coming in and routinely engaging in one type of action that may be expected of "whores" ('putting on a dance for the men'). The fact he negates this possibility ("it's not like you....") is an important face-saving move for both of them; nevertheless, the very act of imagining the possibility projects and preserves the sexualized nature of F's use of "whore", thus maintaining a flirtatious environment of affiliation.

This flirtatious environment ripens across lines 13-16, as F and $\mathrm{M}$ use laughter and innuendo to escalate the imagined-but-unknown possibility of mischievous speed-dating behavior behind closed doors. In line 17, F ratifies that they were indeed in this play frame by shifting out of it with the turn-initial "naw", followed by a re-indexing and two-part rejection of the scripted nature of her and the other women ("we") not engaging ("definitely didn't") in the behavioral features of "whores'. Her "oh my", embedded between her two denials, amplifies her own surprise in having just imagined such possibilities with $M$, which works to further distance herself from the playful allusion to the category "whore". M's "ah too bad" in line 19 not only appreciates and affiliates with F's denial and clarification, but also maintains the flirtatious environment by feigning disappointment. F closes the sequence by laughing and appreciating M's flirtatious disappointment, with her terminal "oh boy" working in unison with her "oh my" in noticing (while also enjoying) having unexpectedly gone too far. Though rife with the potential for disaffiliation, excerpts like this, where insults were exaggerated, tended to function as intimacy pursuits.

\section{Discussion}

The present study used a discursive approach to examine the ways select improprieties were sequentially ordered to pursue intimacy in first encounters between partners in speed-dating events. Rather than functioning as adversarial or stance disaffiliating discursive resources, the improprieties in the present study were, surprisingly, generally relationally constructive, allowing conversational partners to establish repartee and affiliation. Rather than derail topic expansion or stymie the potential for speaker alignment, improprieties were often harbingers of mutual affective stance affiliation, or intimacy pursuits. In the present corpus, negative category attributions of non-present others and insults to the present conversational partner were the most common and consequential forms of impropriety for pursuits of intimacy. Each of these types of impropriety engendered unique strategies of intimacy pursuit between speed-daters.

With respect to negative category attributions of non-present others (NCA's), two conspicuous patterns of intimacy pursuit were common. First, the recipients of such disclosures tended to orient to the negative attributions as if they themselves might be implicated, and would thus work to differentiate themselves from such categories of persons, which often resulted in affiliation. Moreover, the differentiation often reflected a general 5-step pattern. NCAs were generally initiated in a hedged way, but were taken up as incipient actions around which the recipient would both display understanding and elaborate on the features of such NCAs. Both speakers were thus able to display shared cultural knowledge. This worked as a preliminary for the originator of the NCA to expand on the NCA, a move that typically prefaced contrasting differentiation from the recipient speaker. This differentiation was appreciated by the other, resulting mutual affiliation/intimacy. In other cases, speakers would self-select a NCA about their own identity category, and would ease into a process of both formulating and soliciting differentiation, a process that segued with the establishment of affiliation.

At other times, speakers would escalate or upgrade the NCA in order to pursue intimacy. Escalations occurred most often by a speaker who was ostensibly a member of the category implicated by a NCA that was self-selected. In this sense, the escalation seemed strategic (though not necessarily consciously strategic). Like differentiation, escalations of NCAs were often patterned. A speaker would occasion a self-indicting NCA, which solicited affiliation from the other speaker, albeit mitigated affiliation. The affiliation, however tentative, paved the way for the initial speaker to then escalate the NCA, which was typically met with alignment and affiliation from the other. In the terminal environment of such sequences, clear co-affiliation was always present, as well as a mutual appreciation for the type of social activity being engaged in. In sum, there seemed to be 
something interpersonally satisfying, disarming, and ultimately affiliative about sharing negative category ascriptions, and this was true whether the categories applied to the speakers or not.

Speakers also pursued intimacy by exploiting the impropriety of delivering insults to their speed-dating partner. Unlike ritualized insults or verbal duels, the insults featured here functioned more like teases or flirtatious invitations to build solidarity through a shared transgression or knowledge of socio-relational norms. Often, the recipients of such insults, rather than reacting in an adversarial way (disagreement, counter attacks, etc), surprisingly tended to agree with the insult. Insults tended to be met with a knowing or obvious (sine dicendo) rhetorical formulation of agreement, which worked to treat the insult as innocuous, expected, and thus benign. As stated, sine dicendo formulations of agreement attend to the subject- and recipient-side risks of doing insults and being the recipient of insults. They position the insulter as playfully (and not seriously) aggressive, the recipient as unthreatened (if not mildly amused), and the relationship as cooperatively in sync around shared cultural knowledge. Agreement was also laced with laughter or feigned surprise, which both treated the insult as an unserious playful provocation, and invited a jocular participatory frame. Agreement with insults thus became a preliminary for what could be colloquially glossed as a flirtatious play frame that functioned to pursue intimacy.

Insults were also often met with exaggerated or caricatured responses. The exaggerated responses generally took the form of subject-side asymmetrical overreactions ("oh terrified"; "I feel like such a whore") that ratcheted up a subjective self-position to the point of absurdity. Absurdity, as Antaki (2003) notes, is good interactive camouflage. Unlike a po-faced or serious response (see Drew, 1987), absurd sounding receipts project a kind of levity that is not easily countered or undermined. Further, they can be retracted or laughed off quite easily. This suggests that exaggeratedly absurd sounding retorts to insults might function as an indirect way to dismiss or dilute the insult itself and, by extension, to attend to the subject-side risks of both the one formulating the insult and the one receiving it. In short, exaggerations and caricatures of insults tended to render the insult as innocuous, the person delivering the insult as playfully provocative, and the recipient as unthreatened, if not mildly entertained. The cascade effect was always content alignment (the speakers ended up agreeing at the level of content) and, most importantly, affective affiliation (intimacy pursuit).

In general, improprieties seemed to be useful for pursuing intimacy precisely because they seemed, at least at the surface level, to be troublesome. At first blush, this may seem counterintuitive given that theories of interpersonal attraction generally stress the importance of socially desirable actions/behaviors during the initial onset of a relationship. However, when considering the interactional flow of first encounters in a series of speed-dating events, where speakers are vying against others for potential partners, there is likely a press to do or say things that stand out or are idiosyncratic. Being normatively polite may be tantamount to being forgettable in the arena of initial romantic dating. As such, although spontaneously non-normative discursive acts, like improprieties, may be less socially desirable or safe, they may work well as preliminaries for moments of memorable repartee. This seems particularly true if the impropriety is formulated and responded to in non-adversarial ways. Speed-daters may therefore stand out to one another when they delve into the more risky arena of using improprieties, provided they are able to tilt the impropriety away from trouble and towards commensurate affective stance affiliation. Improprieties may thus engender intimacy pursuits because they increase a subjectively shared sense of familiarity. In short, they may be useful for creating interactional sequences that allow the speed-daters to feel like they 'get one another's style' or are 'connecting'.

More traditional explanations as to why improprieties might engender intimacy might rely on attribution theories (see Weaver \& Bosson, 2011), arguing that non-normative actions (like the use of improprieties) tend to be attributed to the person's disposition, which perceivers will infer reveals something about the speaker's true underlying feelings, which makes that person more likable. In contrast, normatively positive actions/statements are less informative, and therefore less likely to promote interpersonal liking. In short, the mechanism for intimacy lies within as an internal dispositional preference for transparency. One central aim of this study was to resist this kind of internal cognitive model. Instead, the aim was draw attention towards an analysis of the actual speed-dating interactions, to see the interactional order itself as the catalyst for intimacy pursuits, and to analyze it as the proper object of inquiry. A sequential-discursive perspective focuses on the ways social practices, like the use of improprieties, are oriented to action and how those actions are co-constructed within unfolding sequential interaction. When approached this way, the utility of improprieties is not taken to be a manifestation of an inner psychological disposition, but is an emergent and responsive social practice to the business of speed-dating. Improprieties are interactional tools with an interactional design that has relational consequences for the ways potential romantic partners pursue intimacy. In sum, the ways potential romantic partners affiliate around the use of non-normative improprieties is consequential for the development of a close relationship. 


\section{References}

Abraham, R. D. (1974). Black talking on the streets. In R. Bauman \& J. Sherzer (Eds)., Explorations in the ethnography of speaking (pp. 337-73). Cambridge: Cambridge University Press.

Antaki, C. (2003). The uses of absurdity. In H. van de Berg, M. Wetherell, \& H. Houtkoop-Steenstra (Eds.), Analyzing race talk: Multidisciplinary perspectives on the research interview (85-102). Cambridge, MA: Cambridge University Press.

Bergmann, J. (1993). Discreet indiscretions. The social organization of gossip. New York: Aldine De Gruyter.

Bolden, G.B. (2008). "So what's up?": Using the discourse marker so to launch conversational business. Research on Language and Social Interaction, 41, 302-337. http://dx.doi.org/10.1080/08351810802237909

Chiou, W. (2006). Adolescents' sexual self-disclosure on the Internet: Deindividuation and impression management. Adolescence, 41, 547-561.

Clark, C., Paul, D., \& Pinch, T. (2003). Managing prospect affiliation and rapport in real-life sales encounters. Discourse Studies, 5, 5-31.

Conroy, T. M. (1999). "I don't want to burst your bubble": Affiliation and disaffiliation in a joint accounting by affiliated pair partners. Human Studies, 22, 339-59. http://dx.doi.org/10.1023/A:1005452904364

Drew, P. (1987). Po-faced receipts of teases. Linguistics, 25, 219-253. http://dx.doi.org/10.1515/ling.1987.25.1.219

Drew, P., \& Walker, T. (2009). Going too far: Complaining, escalating and disaffiliation. Journal of Pragmatics, 41, 2400-2414. http://dx.doi.org/10.1016/j.pragma.2008.09.046

Eastwick, P. W., \& Finkel, E. J (2008). Sex differences in mate preferences revisited: Do people know what they initially desire in a romantic partner? Journal of Personality and Social Psychology, 94, 245-264. http://dx.doi.org/10.1037/0022-3514.94.2.245

Edley, N., \& Wetherell, M. (1997). Jockeying for position: the construction of masculine identities. Discourse and Society, 8 (2), 203-217. http://dx.doi.org/10.1177/0957926597008002004

Edwards, D. (1995). Two to tango: Script formulations, dispositions, and rhetorical symmetry in relationship troubles talk. Research on Language and Social Interaction, 28, 319-350. http://dx.doi.org/10.1207/s15327973rlsi2804_1

Edwards, D. (2005). Moaning, whinging and laughing: The subjective side of complaints. Discourse Studies, 7 , 5-29.

Edwards, D. (2007). Managing subjectivity in talk. In A. Hepburn \& S. Wiggins (Eds.), Discursive research in practice: New approaches to psychology and interaction (pp. 31-49). Cambridge, UK: Cambridge University Press. http://dx.doi.org/10.1017/CBO9780511611216.002

Edwards, D., \& Potter, J. (1992). Discursive Psychology. London: Sage.

Emmertson, S., \& Heinemann, T. (2010). Realization as a device for remedying problems of affiliation in interaction. Research on Language and Social Interaction, 43, 109-132. http://dx.doi.org/10.1080/08351811003738059

Evaldsson, A. (2005). Staging insults and mobilizing categorizations in a multiethnic peer group. Discourse and Society, 16, 763-786. http://dx.doi.org/10.1177/0957926505056663

Finkel, E. J., Eastwick, P. W., Matthews, J. (2007). Speed dating as an invaluable tool for studying romantic attraction: A methodological primer. Personal Relationships, 14, 149-166. http://dx.doi.org/10.1111/j.1475-6811.2006.00146.x

Fisman, R., Iyengar, S. S., Kamenica, E., \& Simpson, I. (2006). Gender differences in mate selection: Evidence from a speed dating experiment. Quarterly Journal of Economics, 121, 673-697. http://dx.doi.org/10.1162/qjec.2006.121.2.673

Georgakopoulou, A. (2002). Narrative and identity management: Discourse and social identities in a tale of tomorrow. Research on Language and Social Interaction, 35, 427-451. http://dx.doi.org/10.1207/S15327973RLSI3504_2

Glenn, P. (2003). Laughter in interaction. Cambridge: Cambridge University Press. http://dx.doi.org/10.1017/CBO9780511519888 
Goffman, E. (1971). Relations in public. New York: Harper Colophon Books.

Goldberg, J. (1978). Amplitude shift: A mechanism for the affiliation of utterances in conversational interaction. In J.N. Schenkein (Ed.), Studies in the organization of conversational interaction (pp. 199-218). New York, NY: Academic Press.

Goldsmith, D., \& Baxter, L. A. (1996). Constituting relationships in talk: A taxonomy of speech events in social and personal relationships. Human Communication Research, 23, 87-114. http://dx.doi.org/10.1111/j.1468-2958.1996.tb00388.x

Goodwin, M. (1990). He-said-she-said: Talk as social organization among black children. Bloomington: Indiana University Press.

Heritage, J. (1985). Analyzing news interviews: Aspects of the production of talk for an overhearing audience. In T. van Dijk (Ed.), Handbook of discourse analysis, Vol.3, discourse and dialogue (pp. 95-117). London: Academic Press.

Houser, M. L., Horan, S. M., \& Furler, L. A. (2008). Dating in the fast lane: How communication predicts speed-dating success. Journal of Social and Personal Relationships, 25, 749-768. http://dx.doi.org/10.1177/0265407508093787

Hutchby, I. (1996). Confrontation talk: Arguments, asymmetries, and power on talk radio. Mahwah, NJ: Lawrence Erlbaum.

Jefferson, G. (2004). Glossary of transcript symbols with an introduction. In G. Lerner (Ed.), Conversation analysis: Studies from the first generation (pp. 13-31). Amsterdam: John Benjamins.

Kochman, T. (1983). The boundary between play and non-play in black dueling. Language in Society, 12, 329-37.

Heritage, J. (1984). A change-of-state token and aspects of its sequential placement. In J. M. Atkinson \& J. Heritage (Ed.). Structures of social action (pp. 299-345). Cambridge, UK: Cambridge University Press.

Korobov, N. (2011a). Mate-preference talk in speed-dating conversations. Research on Language and Social Interaction, 44, 166-189.

Korobov, N. (2011b). Gendering desire in speed-dating interactions. Discourse Studies, 13, 461-485.

Janes, L. M., \& Olsen, J. M. (2000). Jeer pressure: The behavioral effects of observing ridicule of others. Personality and Social Psychology Bulletin, 26, 474-485.

Jefferson, G., Harvey, S., \& Emmanuel, S. (1987). "Notes on Laughter in the Pursuit of Intimacy.” In G. Button and J. Lee, Eds. Talk and Social Organization, pp. 152-205. Clevedon, UK: Multilingual Matters.

Mandelbaum, J. (1987). Couples sharing stories. Communication Quarterly, 35, 144-171. http://dx.doi.org/10.1080/01463378709369678

Mandelbaum, J. (2003). Interactive methods for constructing relationships. In P. Glenn, C. LeBaron, \& J. Mandelbaum (Eds.), Studies in language and social interaction: In honour of Robert Hopper (pp. 207-220). Mahwah, NJ: Lawrence Erlbaum and Associates.

Nosko, A., Wood, E., \& Molema, S. (2010). All about me: Disclosure in online social networking profiles: The case of Facebook. Computers in Human Behavior, 26, 406-418.

Pomerantz, A. (1978). Compliment responses: Notes on the co-operation of multiple constraints.

In J. Schenkein (Ed.), Studies in the organization of conversational interaction (pp. 79-112). New York: Academic Press.

Pomerantz, A. (1984). Agreeing and disagreeing with assessments: Some features of preferred/dispreferred turn shapes. In J.M. Atkinson \& J. Heritage (Eds.), Structures of social action: Studies in conversation analysis (pp. 57-101). Cambridge: Cambridge University Press.

Pomerantz, A., \& Mandelbaum, J. (2005). A conversation analytic approach to relationships: Their relevance for interactional conduct. In K. Fitch \& R.E. Sanders (Eds.), Handbook of language and social interaction (pp. 149-171). Mahwah, NJ: Lawrence Erlbaum and Associates.

Rampton, B. (1995). Crossing: Language and ethnicity among adolescents. London: Longman.

Rampton, B. (1999). Styling the other: Introduction. Journal of Sociolinguistics, 3, 421-427. http://dx.doi.org/10.1111/1467-9481.00088 
Ruusuvuori, J. (2005). "Empathy" and "sympathy" in action: Attending to patients' troubles in Finnish homeopathic and general practice consultations. Social Psychology Quarterly, 68, 204-222.

Sacks, H. (1978). Some technical considerations of a dirty joke. In J.N. Schenkein (Ed.), Studies in the organization of conversational interaction (pp. 249-70). New York, NY: Academic Press.

Speer, S., \& Potter, J. (2000). The management of heterosexist talk: Conversational resources and prejudiced claims. Discourse \& Society, 11(4), 543-572.

Steensig, J., \& Drew, P. (2008). Introduction: Questioning and affiliation/disaffiliation in interaction. Discourse Studies, 10, 5-15.

Stivers, T. (2008). Stance, alignment, and affiliation during storytelling: When nodding is a token of affiliation. Research on Language and Social Interaction, 41, 31-57.

Stokoe, E. (2004). "Gender and Discourse, Gender and Categorization: Current Developments in Language and Gender Research. Qualitative Research in Psychology, 1, 107-29.

Stokoe, E. (2006). On ethnomethodology, feminism, and the analysis of categorical reference to gender in talk-in-interaction. Sociological Review, 54, 467-94. http://dx.doi.org/10.1111/j.1467-954X.2006.00626.x

Stokoe, E. (2008). Categories and sequences: Formulating gender in talk-in-interaction. In K. Harrington, L. Litosseliti, H. Saunston \& J. Sunderland (Eds.), Gender and Language Research Methodologies (pp. 139-157). Basingstoke: Palgrave.

Stokoe, E. (2010a). Gender, conversation analysis, and the anatomy of membership categorization practices. $\begin{array}{lllll}\text { Social and Personality Pschology } & \text { Compass, } & 4, & \text { 428-438. }\end{array}$ http://dx.doi.org/10.1111/j.1751-9004.2010.00261.x

Stokoe, E. (2010b). 'Have you been married, or...?': Eliciting and accounting for relationship histories in speed-dating encounters. Research on Language and Social Interaction, 43, 260-282. http://dx.doi.org/10.1080/08351813.2010.497988

van der Houwen, F. (2009). Formulating disputes. Journal of Pragmatics, 41, 2072-2085. http://dx.doi.org/10.1016/j.pragma.2009.02.009

Waring, H. Z. (2005). The unofficial business of repair initiation: Vehicles for affiliation and disaffiliation. In A. Tyler (Ed.), Language in use: Cognitive and discourse perspectives on language and language learning (pp. 163-75). Washington, DC: Georgetown University Press.

Weaver, J. R., \& Bosson, J. (2011). I feel like I know you: Sharing negative attitudes of others promotes feelings of familiarity. Personality and Social Psychology, 37, 481-491. http://dx.doi.org/10.1177/0146167211398364

Weisbuch, M., Ivcevic, Z., \& Ambady, N. (2009). On being liked on the web and in the 'real' world: Consistency in first impressions across personal webpages and spontaneous behavior. Journal of Experimental Social Psychology, 45, 573-576. http://dx.doi.org/10.1016/j.jesp.2008.12.009

Widdicombe, S., \& Wooffitt, R. (1995). The language of youth subcultures. Social identity in action. New York: Harvester Wheatsheaf.

Valkenburg, P. M., \& Peter, J. (2009). The effects of instant messaging on the quality of adolescents' existing friendships: A longitudinal study. Journal of Communication, 59, 79-97.

\section{(cc) BY}

This work is licensed under a Creative Commons Attribution 3.0 License. 